\section{Utlevering av analgetika til barn før og etter nye anbefalinger om kodein}

ORIGINALARTIKKEL

\section{OLAV MAGNUS S. FREDHEIM}

Palliativt senter

Akershus universitetssykehus

og

Institutt for sirkulasjon og bildediagnostikk

Norges teknisk-naturvitenskapelige universitet

Han hadde ideen til studien, lagde første utkast til analysestrategi og skrev første utkast til artikkelen. Olav Magnus S. Fredheim (f. 1979) er overlege ved Palliativt senter, Akershus universitetssykehus og professor i anestesiologi og smertemedisin ved Norges teknisk-naturvitenskapelige universitet. Forfatter har fylt ut ICMJE-skjemaet og oppgir ingen interessekonflikter.

\section{SVETLANA SKURTVEIT}

Avdeling for psykiske lidelser Folkehelseinstituttet

og

Senter for rus- og avhengighetsforskning

Institutt for klinisk medisin

Det medisinske fakultet

Universitetet i Oslo

Hun ga innspill til analysestrategien, utførte datahåndtering og analyser, og reviderte artikkelen. Svetlana Skurtveit (f. 1962) er seniorforsker ved Avdeling for psykiske lidelser, Folkehelseinstituttet, og professor i rus- og avhengighetsmedisin ved Senter for rus og avhengighetsforskning (SERAF), Universitetet i Oslo.

Forfatter har fylt ut ICMJE-skjemaet og oppgir ingen interessekonflikter.

\section{PETTER C.BORCHGREVINK}

Nasjonal kompetansetjeneste for sammensatte symptomlidelser

og

Institutt for sirkulasjon og bildediagnostikk

Det medisinske fakultet

Norges teknisk-naturvitenskapelige universitet

og

Avdeling for smerte og sammensatte symptomlidelser

Klinikk for anestesi og akuttmedisin

St. Olavs hospital

Petter C. Borchgrevink ga innspill til analysestrategien og reviderte artikkelen.

Petter C. Borchgrevink (f. 1952) er avdelingssjef og avdelingsoverlege ved Avdeling for smerte og sammensatte symptomlidelser, St. Olavs hospital, professor i anestesiologi og smertemedisin ved Norges teknisk-naturvitenskapelige universitet, og leder av Nasjonal kompetansetjeneste for sammensatte symptomlidelser.

Forfatter har fylt ut ICMJE-skjemaet og oppgir ingen interessekonflikter. 


\section{BAKGRUNN}

Sommeren 2013 frarådet Statens legemiddelverk å forskrive kodeinholdige analgetika til barn under 12 år. Bakgrunnen var risikoen for alvorlig respirasjonsdepresjon hos barn med ultrarask omdanning av kodein til morfin. Vi undersøkte i hvilken grad denne anbefalingen er blitt fulgt, og hvilken påvirkning det fikk på utleveringen av andre analgetika på resept.

\section{MATERIALE OG METODE}

Observasjonsstudien er basert på Reseptregisteret, som inneholder komplette data over alle utleveringer av reseptbelagte legemidler i Norge. Det er hentet ut data om alle utleveringer av analgetika på resept til barn til og med 12 år i årene 2011-15.

\section{RESULTATER}

Antall barn under 12 år som fikk utlevert kodein 2011-15 var henholdsvis 4,8 - 5,1 - 4,4 - 1,7 - o,8 per 1 ooo barn per år. Fra 2011 til 2015 falt antallet som fikk utlevert analgetika på resept fra 15,1 til 13,3 per 1 ooo barn per år. I samme periode $\emptyset$ kte antallet barn under 12 år som fikk utlevert andre opioider enn kodein fra o,og til o,20 per 1 ooo barn per år.

\section{FORTOLKNING}

Fordi man parallelt med fallet i forskrivningen av kodeinholdige analgetika ikke hadde en tilsvarende økt forskrivning av andre analgetika, kan smertebehandlingen av barn $<12$ år ha blitt dårligere i denne perioden.

Sommeren 2013 gikk Statens legemiddelverk (SLV) ut med en anbefaling om å ikke forskrive analgetika som inneholder kodein til barn under 12 år (1). Bakgrunnen var kasuistikker hvor man beskrev respirasjonsdepresjon hos barn som ble behandlet med kodein (2). Dette rådet var i samsvar med internasjonale anbefalinger (3). En viktig årsak til disse tilfellene med respirasjonsdepresjon har trolig vært hvordan kodein omdannes til morfin via CYP2D6. Genetiske polymorfismer avgjør i hvilken grad og hvor hurtig denne omdanningen skjer. Hos omtrent $10 \%$ skjer det ikke en slik omdanning, mens det hos 1-2 \% skjer en svært hurtig omdanning (4). De som ikke metaboliserer kodein til morfin får ikke noen smertestillende effekt av kodein, mens de som metaboliserer svært hurtig, får en raskt innsettende og kraftig morfineffekt (5).

Norge er blant de landene med høy bruk av kodein-paracetamol til barn (6). Av norske barn og ungdommer som fikk utlevert et opioid i årene 2005-07, fikk mellom 93 og 95\% kodeinparacetamol, og 95\% mottok kun én eller to utleveringer i løpet av et år (7).

Formålet med denne studien er å belyse hvordan anbefalingen om å unngå kodein til barn under 12 år har påvirket forskrivningen av analgetika til denne pasientgruppen. Vi stilte to konkrete forskningsspørsmål: I hvor stor grad, og hvor raskt etter anbefalingen, kunne man se fallende bruk av kodein til barn under 12 år? Og har det vært en økning i bruken av andre smertestillende legemidler til barn under 12 år i den samme perioden?

\section{Materiale og metode}

\section{STUDIEDESIGN OG DATAKILDE}

Studien er en observasjonsstudie basert på flere sett med tverrsnittsdata fra det komplette nasjonale norske Reseptregisteret. Reseptregisteret inneholder data på individnivå for alle utleveringer av legemidler til personer i Norge. Dataene er pseudonymiserte, men forskrivninger til enkeltpersoner kan studeres over tid. Registeret har ikke data på individnivå for bruk av legemidler i sykehus og sykehjem. Reseptfritt salg av håndkjøpspreparater registreres heller ikke på individnivå. Registeret inneholder blant annet data om legemiddel, legemiddelform, mengde, tidspunkt for ekspedering, eventuell 
refusjon og grunnleggende demografisk informasjon om pasienten.

\section{STUDIEPOPULASJON}

Studiepopulasjonen er alle norske barn til og med 12 år i henholdsvis 2011, 2012, 2013, 2014 og 2015 som fikk utlevert analgetika på resept. I denne studien er barn definert som under 12 år i hele det kalenderåret de fylte 12 år.

\section{MEDIKAMENTER}

I analysen inngår opioidanalgetika i Anatomisk terapeutisk kjemisk (ATC)-gruppen No2A, paracetamol (ATC-kode No2BE01), ikke-steroide antiinflammatoriske midler (non-steroidal anti-inflammatory drugs, NSAID), inkludert selektive hemmere av cyklooksygenase-2 (ATCgruppe Mo1AB-H). Kodeinholdige antitussiva er kodet i en annen ATC-gruppe (Ro5DAo4; Ro5DA20) enn opioidanalgetika, og inngår derfor ikke i studien.

\section{STATISTIKK OG ANALYSESTRATEGI}

Alle barn til og med 12 år som fikk utlevert analgetika på resept, ble identifisert for hvert av årene 2011-15. Alder ved utgangen av hvert år ble brukt som grunnlag for å identifisere studiepopulasjonen og for stratifisering.

Studiepopulasjonen ble stratifisert etter kjønn og alder. Populasjonen er ikke et utvalg, men utgjør hele den aktuelle delen av befolkningen. Resultatene består av deskriptive data. Data om totalt antall barn under 12 år i befolkningen er hentet fra Statistisk sentralbyrå (8).

\section{ETIKK}

Bruken av data fra Reseptregisteret er regulert i egen forskrift. Studien er basert på pseudonymiserte data fra Reseptregisteret, og det kreves ikke behandling av Regional komité for medisinsk og helsefaglig forskningsetikk.

\section{Resultater}

\section{STUDIEPOPULASJON}

Hvert år i perioden 2011-15 mottok fra 11345 til 9934 barn under 12 år analgetika på resept (tab 1). Studiepopulasjonen utgjør årlig mellom 1,2 og 1,4\% av alle norske barn i denne aldersgruppen. Fra 2011 til 2015 falt det totale antallet som fikk utlevert analgetika på resept fra 15,1 til 13,3 per 1 ooo barn per år (tab 2 og fig 1). Andelen jenter varierte mellom $47 \%$ og 49 \%. Gjennomsnittlig alder var 6,6 til 6,8 år, mens median alder var seks år i hele studieperioden.

\section{Tabell 1}

Studiepopulasjonen av barn under 12 år som fikk utlevert analgetika på resept 2011-15. Data fra Reseptregisteret

\begin{tabular}{|llllll|}
\hline & $\mathbf{2 0 1 1}$ & $\mathbf{2 0 1 2}$ & $\mathbf{2 0 1 3}$ & $\mathbf{2 0 1 4}$ & $\mathbf{2 0 1 5}$ \\
\hline N totalt & 11046 & 11345 & 10978 & 10535 & 9934 \\
\hline N jenter (\%) & $\begin{array}{l}5272 \\
(47,7)\end{array}$ & $\begin{array}{l}5346 \\
(47,1)\end{array}$ & $\begin{array}{l}5256 \\
(47,9)\end{array}$ & $\begin{array}{l}5116 \\
(48,6)\end{array}$ & $\begin{array}{l}4823 \\
(48,6)\end{array}$ \\
\hline Alder, gjennomsnitt & 6,8 & 6,8 & 6,6 & 6,7 & 6,7 \\
\hline Alder, median & 6 & 6 & 6 & 6 & 6 \\
\hline $\begin{array}{l}\text { Andel (\%) av alle barn } \\
\text { under 12 år }\end{array}$ & 1,4 & 1,4 & 1,4 & 1,3 & 1,2 \\
\hline
\end{tabular}




\section{Tabell 2}

Utleveringer av analgetika til barn under 12 år 2011-15, stratifisert på alder

\begin{tabular}{|c|c|c|c|c|c|}
\hline Utleveringer av analgetika ( $N=1000$ barn) & 2011 & 2012 & 2013 & 2014 & 2015 \\
\hline Totalt & 15,10 & 15,45 & 14,86 & 14,18 & 13,29 \\
\hline Kodein & 4,82 & 5,12 & 4,40 & 1,69 & 0,80 \\
\hline Andre opioider & 0,09 & 0,11 & 0,11 & 0,15 & 0,20 \\
\hline Ikke-opioide analgetika & 12,49 & 12,82 & 12,74 & 13,11 & 12,63 \\
\hline \multicolumn{6}{|l|}{ 0-2 år } \\
\hline Kodein & 1,18 & 1,20 & 0,71 & 0,10 & 0,02 \\
\hline Andre opioider & 0,05 & 0,02 & 0,02 & 0,01 & 0,07 \\
\hline Ikke-opioide analgetika & 10,27 & 10,66 & 11,53 & 12,38 & 11,73 \\
\hline \multicolumn{6}{|l|}{ 3-5 år } \\
\hline Kodein & 8,10 & 8,59 & 7,04 & 1,01 & 0,15 \\
\hline Andre opioider & 0,05 & 0,04 & 0,03 & 0,05 & 0,07 \\
\hline Ikke-opioide analgetika & 13,92 & 14,84 & 15,71 & 16,33 & 15,86 \\
\hline \multicolumn{6}{|l|}{ 6-8 år } \\
\hline Kodein & 4,50 & 4,76 & 4,39 & 1,60 & 0,38 \\
\hline Andre opioider & 0,04 & 0,06 & 0,04 & 0,10 & 0,09 \\
\hline Ikke-opioide analgetika & 9,09 & 9,39 & 9,45 & 9,23 & 8,92 \\
\hline \multicolumn{6}{|l|}{ 9-10 år } \\
\hline Kodein & 3,58 & 3,82 & 3,08 & 2,23 & 0,98 \\
\hline Andre opioider & 0,06 & 0,13 & 0,12 & 0,11 & 0,23 \\
\hline Ikke-opioide analgetika & 10,36 & 10,77 & 9,78 & 9,95 & 9,83 \\
\hline \multicolumn{6}{|l|}{$11-12$ år } \\
\hline Kodein & 5,26 & 5,56 & 5,28 & 3,97 & 3,05 \\
\hline Andre opioider & 0,28 & 0,35 & 0,43 & 0,55 & 0,69 \\
\hline Ikke-opioide analgetika & 19,49 & 18,97 & 17,34 & 18,01 & 17,20 \\
\hline
\end{tabular}

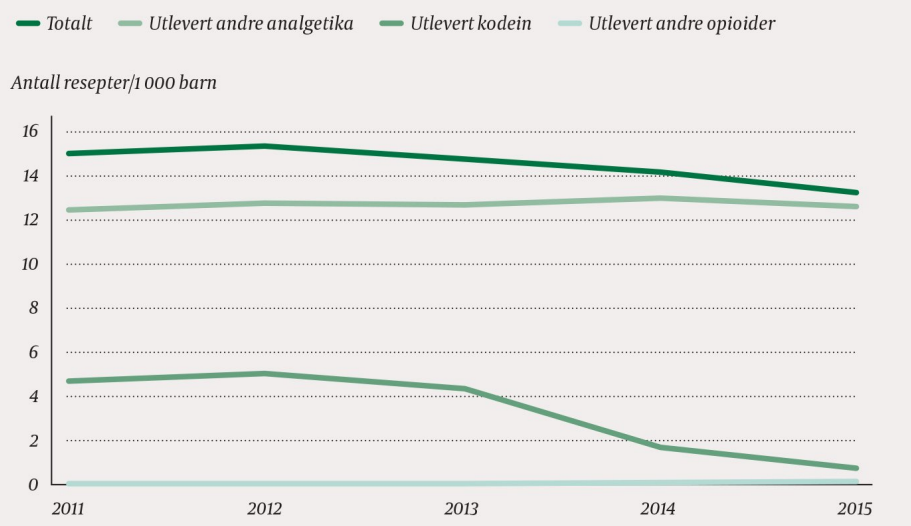

Figur 1 Andel ( $n=1000)$ av barn under 12 år som fikk utlevert analgetika 2011-15. En person kan motta flere ulike typer analgetika i løpet av året. Data fra Reseptregisteret

\section{UTVIKLING I UTLEVERING AV KODEIN}

Antall barn under 12 år som fikk utlevert kodein var i 2011 til 2013 mellom 4,4 og 5,1 per 1000 barn per år (fig 2 og tab 2). I 2014 falt antallet til 1,7 og i 2015 videre til o,8 per 1 ooo barn per år, altså en reduksjon på $82 \%$ fra 2013 til 2015. 


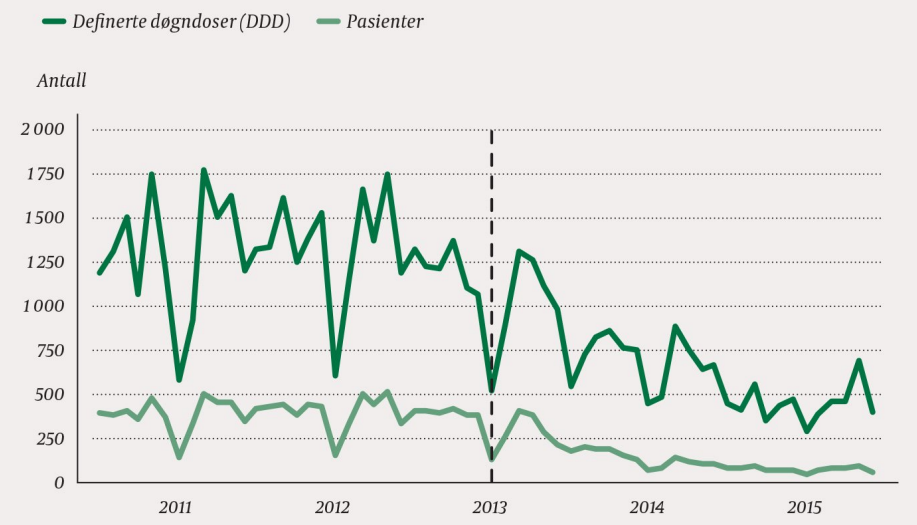

Figur 2 Antall barn under 12 år med utleveringer av kodeinholdige analgetika per måned, og totalt antall definerte døgndoser (DDD) kodeinholdige analgetika utlevert til barn under 12 år per måned. Stiplet vertikal linje indikerer tidspunktet da bruk av kodein til barn under 12 år ble frarådet

Når studiepopulasjonen stratifiseres på alder, ser man en betydelig reduksjon i alle aldersgrupper, men for barn med alder $11 \operatorname{og} 12$ år var reduksjonen kun 42 \% (tab 2). Barn på 11 og 12 år utgjorde 62\% av barn under 12 år som mottok kodein i 2015.

\section{UTVIKLING I UTLEVERING AV ANDRE ANALGETIKA}

I årene 2011-13 var det hvert år mellom o,o9 og o,11 per 1 ooo barn under 12 år som fikk utlevert andre opioider enn kodein. Antallet $\varnothing$ kte til o,15 i 2014 og videre til o,20 i 2015 (tab 2). Tramadol var det mest brukte av andre opioider, fulgt av morfin og oksykodon.

I perioden 2011-15 var det en økning i utlevering av paracetamol på resept til barn under 12 år, mens utleveringen av ikke-steroide antiinflammatoriske midler på resept var stabil (tab 3).

\section{Tabell 3}

Fordeling mellom ulike analgetika utlevert på resept til barn under 12 år 2011-15. En person kan motta flere ulike typer analgetika i løpet av året. Data fra Reseptregisteret

\begin{tabular}{|lcrrrr|}
\hline $\mathbf{N}=\mathbf{1 0 0 0}$ & $\mathbf{2 0 1 1}$ & $\mathbf{2 0 1 2}$ & $\mathbf{2 0 1 3}$ & $\mathbf{2 0 1 4}$ & $\mathbf{2 0 1 5}$ \\
\hline Kodein-paracetamol & 4,45 & 4,72 & 4,05 & 1,56 & 0,74 \\
\hline Paracetamol & 2,57 & 2,59 & 2,84 & 3,37 & 3,54 \\
\hline Ikke-steroide antiinflammatoriske midler & 9,99 & 10,34 & 10,24 & 10,47 & 9,97 \\
\hline Tramadol & 0,04 & 0,06 & 0,07 & 0,08 & 0,08 \\
\hline Morfin & 0,03 & 0,03 & 0,01 & 0,02 & 0,05 \\
\hline Oksykodon & 0,01 & 0,01 & 0,01 & 0,01 & 0,03 \\
\hline Andre opioider & 0,01 & 0,01 & 0,01 & 0,01 & 0,01 \\
\hline
\end{tabular}

\section{Diskusjon}

Denne studien har vist at rådene til Statens legemiddelverk i 2014 om ikke å forskrive kodeinholdige analgetika til barn, raskt førte til en reduksjon på 82 \% i utleveringen av kodein til barn under 12 år. Imidlertid ble ikke denne reduksjonen i utleveringer av kodeinholdige analgetika ledsaget av en tilsvarende økning i utleveringer av andre analgetika på resept, verken andre opioider eller ikke-steroide antiinflammatoriske midler. Fortolkningen av funnet vanskeliggjøres av at det verken foreligger data på om bruken av analgetika før 2014 var på et ideelt nivå, eller data på kvaliteten av smertebehandlingen før og etter 2014 .

Man kan identifisere barn som omdanner kodein ultraraskt til morfin eller ikke omdanner 
kodein til morfin, ved å gjøre en genetisk analyse basert på en blodprøve. Imidlertid er slik testing i praksis ikke gjennomførbar før oppstart av behandling av akutt smerte.

Genotyping kunne derfor ikke ha løst hele problemet i klinisk praksis, selv om man teoretisk kunne utført preoperativ genotyping ved elektiv kirurgi.

Hovedalternativene for å behandle sterke smerter som har krevd bruk av kodeinholdige analgetika, er å enten bruke andre opioider eller høyere doser av kombinasjoner av ikkeopioide analgetika. Tablettstyrken på andre opioidtabletter er dårlig tilpasset de minste barna, men både morfin og oksykodon selges som mikstur slik at man kan måle opp doser som også er tilpasset mindre barn. Ikke-opioide analgetika er effektive ved akutt og postoperativ smerte, særlig når paracetamol og ikke-steroide antiinflammatoriske midler kombineres. For å utnytte potensialet av ikke-opioide analgetika er det trolig viktig med et strukturert opplegg der de skrives ut på resept og forskrives i doser som er tilpasset barnas alder og vekt, fremfor å gi generelle råd om å bruke håndkjøpspreparater. Det er derfor viktig at man i situasjoner der man tidligere forskrev kodein-paracetamol, ikke nøyer seg med å gi generelle råd om å bruke håndkjøpspreparater.

Til tross for 82 \% reduksjon i bruken av kodein viser denne studien at 6oo barn i 2015 fremdeles mottok et legemiddel som i større grad enn alternativene disponerer for livstruende bivirkninger. Imidlertid skal man også være oppmerksom på at for leger som sjelden doserer opioider til barn, vil det ta tid å bli fortrolig med å dosere korrekt et annet opioid enn det man er vant med. Derfor innebærer selve overgangen til bruk av andre opioider trolig også en risiko for både over- og underdosering.

Styrken ved studier basert på data fra Reseptregisteret er at registeret inneholder komplette nasjonale data for utlevering av reseptpliktige legemidler. Den største svakheten er at man ikke vet om de utleverte legemidlene blir brukt av mottakeren. En ytterligere svakhet ved denne studien er at Reseptregisteret ikke gir data på bruk av håndkjøpsanalgetika. Derfor vil bruken av paracetamol og ikke-steroide antiinflammatoriske midler bli underestimert.

Konklusjonen i denne studien er at Statens legemiddelverks velbegrunnede anbefaling om ikke å forskrive kodeinholdige analgetika til barn under 12 år, i stor grad ble fulgt av norske leger. Fordi reduksjonen i bruken av kodein ikke førte til en sammenlignbar økning i bruken av verken andre opioider eller ikke-steroide antiinflammatoriske midler, må man frykte at anbefalingen har ført til dårligere smertebehandling i denne aldersgruppen. Det er viktig at potensialet til kombinasjonsbruk av paracetamol og ikke-steroide antiinflammatoriske midler utnyttes optimalt, og når dette ikke er tilstrekkelig, må pasientene få forskrevet et annet opioid i stedet for kodein.

\section{HOVEDBUDSKAP}

I løpet av to år, etter en anbefaling fra Statens legemiddelverk om å ikke behandle barn under 12 år med kodein, ble forskrivningen av kodeinholdige analgetika til barn redusert med $82 \%$

Det var ingen tilsvarende $ø$ kning i bruken av andre opioider

Det var en svak økning i utleveringen av paracetamol på resept i samme tidsrom, mens utleveringen av ikke-steroide antiinflammatoriske midler på resept var stabil

LITTERATUR:

1. Voronov P, Przybylo HJ, Jagannathan N. Apnea in a child after oral codeine: a genetic variant - an ultra-rapid metabolizer. Paediatr Anaesth 2007; 17: 684 - 7 .

2. Lazaryan M, Shasha-Zigelman C, Dagan Z et al. Codeine should not be prescribed for breastfeeding mothers or children under the age of 12. Acta Paediatr 2015; 104: 550 - 6. 
3. Lötsch J, Geisslinger G. Current evidence for a genetic modulation of the response to analgesics. Pain 2006; 121:1- 5 .

4. Poulsen L, Brøsen K, Arendt-Nielsen L et al. Codeine and morphine in extensive and poor metabolizers of sparteine: pharmacokinetics, analgesic effect and side effects. Eur J Clin Pharmacol 1996; 51: $289-95$.

5. Mahic M, Fredheim OM, Borchgrevink PC et al. Use of prescribed opioids by children and adolescents: Differences between Denmark, Norway and Sweden. Eur J Pain 2015; 19: 1095 - 100.

6. Fredheim OM, Log T, Olsen W et al. Prescriptions of opioids to children and adolescents; a study from a national prescription database in Norway. Paediatr Anaesth 2010; 20: 537 - 44.

7. Statistisk sentralbyrå. Folkemengde og Befolkningsendringar.

https://www.ssb.no/statistikkbanken/selectvarval/Define.asp?subjectcode=\&ProductId=\&MainTableFolkemEttAarig\&nvl=\&PLanguage $=0 \& n y T m p V a r t r u e \& C M S S u b j e c t A r e a b e f o l k n i n g \&$ KortNavnWebfolkemengde\&StatVariant=\&checkedtrue (16.2.2017).

Publisert: 26. juni 2017. Tidsskr Nor Legeforen. DOI: 10.4045/tidsskr.16.0717

Mottatt 28.10.2016, første revisjon innsendt 16.1.2017, godkjent 29.3.2017.

(C) Tidsskrift for Den norske legeforening 2020. Lastet ned fra tidsskriftet.no 